\title{
Construindo Sistemas de Controle em Escolas Urbanas*
}

\author{
LINDA DARLING-HAMMOND \\ Stanford University - School of Education \\ ldh@stanford.edu
}

CAROL ASCHER

New York University - Community Involvement Program

carolascher@nyu.edu

\begin{abstract}
Resumo
As questões referentes ao controle social e à responsabilização têm se tornado constantes na política educacional, apesar de as posições sobre como efetivar tais questões estarem em contínua mudança. Problemas nas escolas têm aumentado a expectativa em torno da criação de sistemas de controle social e responsabilização como incentivo à melhoria e à reestruturação das escolas. Construir um autêntico sistema de controle em escolas de grandes centros urbanos é uma tarefa complexa que implica cuidado, responsabilidade e atenção aos meios para avaliar a eficácia do trabalho escolar e o progresso dos estudantes.

Palavras-chave: controle social, sistemas de avaliação, escolas urbanas.
\end{abstract}

\section{Resumem}

Las cuestiones referentes al control social y a la responsabilidad correspondiente se han vuelto constantes en la política educacional, a pesar de que los planteamientos sobre cómo resolver tales problemas están cambiando constantemente. Los problemas en las escuelas han aumentado la expectativa alrededor de la creación de sistemas de control social y de responsabilidad como incentivo a la mejora y a la reestructuración de las escuelas. Construir un auténtico sistema de control en escuelas de grandes centros urbanos es una tarea compleja que implica cuidado, responsabilidad y atención a los medios para evaluar la efectividad del trabajo escolar y el progreso de los estudiantes.

Palabras-clave: control social, sistemas de evaluación, escuelas urbanas.

* Creating Accountability in Big City School Systems. Texto publicado originalmente em: ERIC Clearinghouse on Urban Education, Teachers College. New York: Urban Diversity Series, n. 102, March 1991. Disponível em: http://iume.tc.columbia.edu/eric_archive /mono/UDS102.pdf

Traduzido, com autorização das autoras, pelos professores da Universidade Federal do Paraná: Andréa Barbosa Gouveia (andreabg@ufpr.br) e Ângelo Ricardo de Souza (angelo@ufpr.br). 


\begin{abstract}
Accountability has always been a basic concept in public education, although ideas about how to accomplish it have changed over the years. Problems in urban schools have given rise to the hope that carefully created systems of accountability might spur school improvement and school restructuring. Devising a system of genuine accountability in a large urban school is a complex task, involving careful sorting of responsibilities and a thoughtful set of measures for assessing school effectiveness and student progress.

Key words: accountability, assessment systems, urban schools.
\end{abstract}




\section{DETERMINANDO QUEM É RESPONSÁVEL PELO QUÊ E PARA QUEM}

\section{A Natureza do Controle ${ }^{1}$}

A idéia de controle sempre foi um conceito básico importante na educação pública, assim como o é na esfera pública de modo geral, embora as idéias de como atingi-lo tenham mudado. No campo da educação, o sistema de controle implica não apenas que professores, dirigentes escolares e outros profissionais da escola sejam responsáveis perante os pais, os outros cidadãos e seus representantes eleitos, mas também que os pais tenham a responsabilidade de mandar seus filhos à escola.

Recentemente, problemas na escolarização urbana têm difundido a idéia de que sistemas de controle bem elaborados podem contribuir para a melhoria e até para a reestruturação das escolas (McDonnell, 1989). Obviamente, o "controle natural", ou seja, o contato frente a frente, como ocorre em pequenas comunidades, é impossível de ser realizado em grandes escolas urbanas. Os distritos escolares urbanos podem abranger áreas bastante extensas, além de atenderem a populações diversas e funcionarem em diferentes níveis burocráticos ${ }^{2}$. O objetivo é, portanto, a criação de estruturas planejadas para que as escolas e os distritos possam assegurar mecanismos de controle que sejam iguais ou melhores do que aqueles do tipo "natural".

Fica evidente, então, que planejar um sistema de controle genuíno é uma tarefa complexa que envolve uma cuidadosa definição de responsabilidades, além de um bem-elaborado conjunto de medidas para avaliar a eficácia da escola e o progresso dos estudantes. Toda tentativa de implementar um sistema de controle em uma grande escola urbana deve envolver três questões: "Quem é o responsável? Pelo quê? E para quem?" (OERI State Accountability Study Group, 1989). As respostas para essas questões não são fáceis de estabelecer e é provável que um sistema de controle baseado nelas venha a ser multifacetado e complexo.

Ainda que o objetivo seja tornar os professores responsáveis pela qualidade da aprendizagem, determinados métodos voltados a este fim restringem as práticas escolares de tal forma que, na verdade, fazem com

\footnotetext{
1 Optamos por traduzir accountability como controle, entendendo que o termo tem um sentido complexo de controle externo coletivo ou individual que cria responsabilização sobre os processos em discussão. (Nota dos tradutores)

2 Nos EUA, há uma importante estrutura do sistema de ensino, denominado Distrito, que é uma definição geopolítica educacional, para a qual parece não haver equivalente no Brasil. Trata-se de uma área na qual há um conjunto de escolas e sobre a qual recaem políticas e tarefas educativas específicas. (Nota dos tradutores)
} 
que os alunos aprendam menos. Em razão de tais complicações, não é de surpreender que os gestores de sistemas de ensino tenham freqüentemente recorrido à estratégia aparentemente mais fácil - o monitoramento dos estudantes por via de notas em testes -, e tenham até, eventualmente, ligado suas decisões fundamentais (promoções, graduações, premiações ou sanções de professores e escolas) aos resultados desses testes, provavelmente como meio de alcançar certa responsabilidade.

No entanto, indicadores de desempenho, como notas em testes e taxas de evasão, são informações para um sistema de controle, não são o sistema em si. O controle (isto é, a prática responsável e responsabilidade para com o usuário) ocorre apenas quando existe um conjunto de processos úteis para a interpretação e para a ação, baseados nessas informações. De fato, se os indicadores escolares são projetados de forma imprópria ou usados de maneira não inteligente, podem até enfraquecer o sistema de controle.

\section{O Controle como um Sistema}

Um sistema de controle é um conjunto de compromissos, políticas e práticas que têm a finalidade de:

1) aumentar a probabilidade de os estudantes serem expostos a boas práticas de ensino em um ambiente que estimula a aprendizagem;

2) reduzir a probabilidade da adoção de práticas prejudiciais; e

3) permitir auto-correções internas no sistema para identificar, diagnosticar e mudar o curso de ações que sejam prejudiciais ou ineficazes.

Os dados provenientes das avaliações são informações relevantes, válidas e oportunas sobre o quanto os estudantes estão aprendendo individualmente e quão bem as escolas os estão atendendo. Mas esse tipo de dado é apenas uma pequena parte do processo de controle. $\mathrm{O}$ controle também inclui questões sobre como uma escola ou o sistema a que ela pertence contrata, avalia e dá suporte à sua equipe; como se relaciona com os estudantes e os pais; como lida com os afazeres cotidianos; como toma decisões; como assegura que o melhor conhecimento disponível será adquirido e utilizado; como avalia seu próprio funcionamento, assim como o progresso dos alunos; como lida com os problemas; e como garante incentivos que permitam a melhoria contínua da escola. 


\section{Tipos de Controle na Educação}

Em educação, como em outras instituições de nossa sociedade, é possível destacar pelo menos cinco tipos de mecanismos de controle que co-existem (Darling-Hammond, 1989).

- Controle político: os legisladores e os membros da direção da escola, por exemplo, devem se submeter regularmente a processos eleitorais.

- Controle legal: os cidadãos podem recorrer à justiça para denunciar práticas escolares que violem a legislação; por exemplo, desagregação ou falta de eqüidade nas oportunidades educacionais.

- Controle burocrático: distritos e órgãos do sistema educacional aprovam normas e regulamentos para garantir que o ensino siga determinados padrões.

- Controle profissional: os professores e todos os outros membros da equipe escolar devem possuir conhecimento especializado, obter certificação e manter padrões de prática profissional.

- Controle de mercado: pais e alunos podem escolher cursos ou escolas que considerem mais apropriados. Podem, inclusive, envolver-se em formas mais diretas de participação do processo decisório das escolas.

Cada um desses mecanismos de controle tem suas vantagens e desvantagens, dependendo do objetivo desejado. Os mecanismos de controle político podem ajudar a estabelecer normas políticas gerais, mas não permitem que o cidadão julgue cada decisão dos representantes eleitos e não asseguram, necessariamente, os direitos das minorias. Os mecanismos legais são úteis para estabelecer e defender direitos individuais e de grupos, mas nem todas as decisões educacionais são objeto de ações judiciais e nem todos os cidadãos têm acesso à justiça.

Os mecanismos burocráticos são adequados quando procedimentos padronizados apresentam os resultados desejados, mas podem ser contraproducentes quando os usuários têm necessidades específicas. Os mecanismos profissionais são importantes quando o serviço prestado requer conhecimentos complexos para atender às necessidades individuais dos usuários, mas nem sempre levam em consideração objetivos públicos que se contrapõem, tais como serviços melhores versus a contenção de custos. Por fim, os mecanismos de mercado são úteis quando as preferências do usuário variam muito e o Estado não tem interesse em 
controlar as escolhas possíveis, porém eles não garantem que todos os cidadãos terão acesso a serviços de qualidade.

Em virtude dessas limitações, nenhuma forma de controle pode operar sozinha nas principais áreas da vida pública. A escolha de ferramentas de controle e o equilíbrio entre as diferentes formas de controle modifica-se constantemente conforme apareçam os problemas, mudem os objetivos sociais ou surjam novas circunstâncias.

No caso da educação, o poder do controle político, exemplificado pela autoridade das diretorias das escolas, tem ora se ampliado, ora se diluído, nos últimos 20 anos. No mesmo período, as formas de controle legal têm crescido, uma vez que os tribunais têm sido usados para resolver casos da política educacional; e as formas de controle burocrático também têm-se expandido por meio das ações dos gestores dos sistemas de ensino, no âmbito estadual e distrital. Recentemente, o controle de mercado (a forma menos utilizada de controle) tem-se desenvolvido um pouco com mecanismos como o marketing das escolas, destinado a subsidiar a escolha da escola pelos usuários ${ }^{3}$. Finalmente, baseados na expansão do conhecimento e no esforço em criar padrões mais significativos para as práticas, o controle profissional está ganhando força como meio de melhorar o ensino. Contudo, entre todas essas formas, os mecanismos legal e burocrático têm superado os demais - e alguns especialistas sugerem que essas duas formas podem ter extrapolado seu alcance.

Tendo em vista que as ferramentas de controle burocrático, profissional e de mercado têm sido propostas como estratégias para a melhoria da escola, é importante compreender o que cada uma oferece e em que aspectos podem entrar em conflito.

\section{Controle Burocrático}

A força do controle burocrático está nos seus objetivos de garantir equalização e padronização educacional. Na abordagem burocrática para a administração escolar, as escolas são vistas como órgãos do governo a serem administradas pela hierarquia no processo de tomada de decisões. As políticas são definidas pelas instâncias superiores do sistema, e

\footnotetext{
3 Trata-se de formas que permitem aos familiares dos alunos definirem em qual escola colocarão seus filhos, rompendo-se com o modelo em que o Estado é o responsável por definir quem vai estudar e onde. A idéia de atração promovida pelas escolas está também ligada a essa escolha, pois se elas forem "escolhidas" podem procurar mecanismos para tentar "atrair" os alunos para si. Essa forma de organização tem estado bastante presente nas reformas educacionais dos países anglo-saxões, nos últimos 20 anos. (Nota dos tradutores)
} 
transmitidas aos administradores que as transformam em regras e procedimentos. Os professores seguem tais procedimentos (horários, currículo, livro texto, regras para aprovação e matrícula dos estudantes etc.) e os alunos se orientam por eles.

Esse tipo de controle sugere a possibilidade de se encontrar o "melhor sistema", definido em lei e especificado por regulamentos sob os quais todos os estudantes devem ser educados. O controle burocrático pressupõe que:

1) os alunos sejam suficientemente igualizados para responder de forma idêntica e previsível aos "tratamentos" definidos pelos gestores e seus agentes;

2) o conhecimento de quais tratamentos prescrever esteja disponível e seja generalizável para todas as circunstâncias educativas;

3) esse conhecimento possa ser transformado em regras padronizáveis para a prática, a qual, por sua vez, pode ser mantida por meio de sistemas regulatórios e de inspeção; e

4) os administradores e professores podem e irão implementar fielmente as prescrições na sua prática.

No modelo burocrático, os professores têm a responsabilidade de implementar as políticas curriculares de avaliação, normalmente prescritas pelos Estados e/ou distritos, independentemente de tais prescrições serem apropriadas ou não para cada caso em particular. Os conhecimentos pedagógico e teórico dos professores podem, na verdade, constituir um empecilho se entrarem em conflito com essas políticas. (De fato, os conhecimentos atuais sobre aprendizagem sugerem que tais conflitos irão ocorrer freqüentemente, posto que os estudantes aprendem de formas diversas, em ritmos diferentes, sob diferentes circunstâncias; e as estratégias efetivas de ensino devem ser flexíveis, adaptáveis e não uniformes para satisfazer a essas necessidades). Entretanto, o modelo burocrático não procura garantir ao professor conhecimento aprofundado sobre o processo, pois supõe que muitas decisões importantes sejam tomadas em outros níveis hierárquicos, e os professores apenas as recebam em pacotes prontos. Nesse sistema, os professores não podem ser responsabilizados por satisfazer as necessidades específicas de seus alunos; apenas podem ser cobrados por seguirem os procedimentos operacionais padronizados.

Enquanto o modelo burocrático de controle determina práticas curriculares e instrucionais padronizadas, as opções por uma gestão centrada na escola (a qual dá mais sentido às estratégias de atração e 
escolha de escolas) são também limitadas. Assim, tanto o controle profissional quanto o de mercado podem entrar em conflito com certas formas de controle burocrático.

\section{Controle Profissional}

O controle profissional, quer para médicos, advogados ou professores, começa com um pressuposto bastante diferente do controle burocrático. Enquanto o modelo anterior visava aos objetivos de uniformização e padronização, o controle profissional procura criar práticas orientadas ao público e baseadas no conhecimento técnico. Ele pressupõe que, uma vez que as decisões sobre as diferentes necessidades dos clientes são complexas e específicas demais para serem prescritas a distância, o sistema deve ser estruturado para garantir que os profissionais sejam capazes de tomar decisões responsáveis. Isso implica, portanto, assegurar a competência profissional por meio de rigorosa preparação, certificação, seleção e avaliação, e contínua avaliação pelos pares. Requer que o profissional tome decisões baseadas no melhor conhecimento técnico e que seu compromisso primeiro seja com o bem-estar do cliente.

Em vez de visar a práticas reguladoras, este modelo procura garantir que as pessoas que cuidam dos alunos sejam competentes e comprometidas, como os pais e os próprios alunos esperam. A qualidade da equipe contratada é um dos componentes-chave do controle profissional. Conseqüentemente, esse sistema necessita dar atenção especial ao preparo, à contratação e avaliação dos professores e de outros membros da equipe; ao apoio para a sua contínua aprendizagem e aos meios de avaliação que existem, tanto para avaliar as práticas da escola e de sala de aula quanto para avaliar o progresso dos alunos.

Para os educadores tomarem as decisões intelectuais e éticas inerentes ao controle profissional, devem ter o conhecimento e as habilidades que dão sustentação a uma tomada de decisões responsável. Devem também trabalhar sob menos regras acerca do quê, quando e como ensinar, de modo que possam tomar decisões que atendam às necessidades dos estudantes em vez de atender apenas às regulamentações.

Como o controle profissional está explicitamente relacionado às diferentes necessidades dos estudantes, este modelo se contrapõe, com freqüência, a práticas padronizadas e, portanto, a algumas formas de controle burocrático. Um professor responsável pode decidir que alguns ou todos os seus alunos aprenderiam melhor com livros diferentes dos indicados, por estes estarem mal elaborados, inadequados ao seu nível de 
leitura, ou por representarem, de forma preconceituosa, certos grupos raciais, étnicos ou culturais. $O$ professor sabe que os estilos de aprendizagem de alguns estudantes correspondem melhor a determinados métodos de ensino ou materiais, e não necessariamente aos materiais prescritos para o uso geral, e, baseado no seu conhecimento profissional sobre avaliação, insistiria para que nenhuma decisão sobre nenhum estudante fosse tomada apenas com base em um único resultado de teste ou outra medida padronizada.

O benefício potencial desse tipo de controle está no foco sobre a adequação das decisões às necessidades dos alunos. O problema potencial é que se os padrões profissionais não forem rigorosamente aplicados na preparação e nos procedimentos adotados na prática, as decisões individuais dos educadores podem se tornar idiossincráticas e sem fundamento no conhecimento e na ética profissionais.

\section{Equilíbrio entre Igualdade e Produtividade}

A decisão sobre quais aspectos da educação devem ser delegados ao controle burocrático e quais podem ser delegados ao controle profissional exige que se faça distinção entre os conceitos de igualdade e produtividade (Wise, Glender, 1989). Questões de igualdade devem ser resolvidas geralmente por altas esferas de governo, pois elas resultam do conflito de interesses entre maiorias e minorias e entre grupos que têm poder e grupos que não têm poder, e também porque as instituições locais são muitas vezes reféns de políticas majoritárias e intencionalmente, ou não, discriminam (p.206). Preocupações, tais como a alocação de recursos e garantias de igualdade de acesso, podem e devem ser reguladas pelas instâncias mais altas de governo.

Já as questões de produtividade não podem ser resolvidas com eficácia pelo controle burocrático, pois o conhecimento pedagógico é utilizado de modo altamente individualizado. Assim, as decisões políticas, no âmbito estadual e distrital, sobre métodos de ensino e sobre processos escolares, não podem dar conta das necessidades dos vários contextos de escolas e estudantes. A melhoria do desempenho dos estudantes e das escolas exige decisões diferenciadas e corroboradas pela responsabilidade profissional.

O crescimento das formas burocráticas de controle, nas décadas recentes, tem mostrado que as decisões tomadas de cima para baixo no sistema não podem resolver todos os problemas e que uma superregulação pode, por vezes, minar um sistema de controle. Além de 
prescrever práticas que podem ser inadequadas para certos alunos, um processo decisório hierárquico pode, muitas vezes, acabar não responsabilizando ninguém pelos resultados. Quando o corpo de profissionais da escola não é responsável pelas decisões, também deixa de ser responsável pela busca de soluções para os problemas escolares.

$\mathrm{O}$ fato de que as diferentes necessidades dos estudantes e os diferentes contextos escolares requerem estratégias diferenciadas tem renovado a atenção aos métodos que atribuem maior autoridade e responsabilidade à escola e à sala de aula. Dois conceitos correntes que têm recebido muita atenção são a escolha de escolas, que pretende criar mais controle de mercado, e a gestão centrada na escola, que se baseia em maior controle profissional e político.

\section{Controle de Mercado}

A idéia de uma escola atrativa e outros métodos de escolha são baseados em mecanismos de quase-mercado. Esses mecanismos pretendem tornar as escolas mais responsáveis em, pelo menos, duas formas:

1) ao permitir que os "clientes" escolham, as escolas devem se esforçar mais para oferecer serviços que os alunos e os pais desejam; e

2) ao permitir escolhas, o mercado deve revelar que as escolas com baixa procura têm problemas que deveriam receber a atenção dos legisladores.

Diversas questões são levantadas pela forma atual de mercado. As mais imediatas são: como os estudantes e seus pais escolhem as escolas atualmente? Quais indicadores as escolas devem colocar à disposição de estudantes e de seus pais para que esses sejam consumidores informados sobre a educação pública? Quais medidas positivas, além de mudar de escola, os pais e estudantes podem tomar quando as escolas não atendem às suas necessidades? E que veículos poderiam aumentar o feedback sobre a opinião dos pais e estudantes a respeito da escolaridade? A possibilidade de maior feedback para as escolas e os criadores de políticas, e maiores opções para os consumidores informados estão entre os principais benefícios potenciais dos métodos de escolha.

Contudo, mesmo sob as melhores condições, apenas a escolha de uma escola não é suficiente para garantir o controle do usuário. Por exemplo, quando as melhores escolas não tiverem mais vagas, ainda haverá muitos estudantes para serem matriculados, e um número de 
escolas, atraentes ou não, que deve atendê-los. Se não houver outros mecanismos de políticas públicas que propiciem melhorias nas escolas, as escolhas somente servirão para ajustes marginais na distribuição dos estudantes em algumas escolas, e não produzirão uma melhoria generalizada na qualidade de ensino.

Não é de surpreender que o controle de mercado possa criar tensões com outras formas de controle. Uma vez que o controle burocrático padroniza o que é oferecido em diferentes escolas, ele minimiza a escolha informada. Mesmo que o controle profissional implique orientação ao cliente, a participação dos pais pode ser problemática para os professores, pois decisões baseadas no conhecimento profissional podem não coincidir com os desejos dos pais.

Finalmente, o controle na educação pública tem tradicionalmente aceitado que o Estado, o distrito e a escola sejam responsáveis, em diferentes níveis, pela educação pública: o primeiro é responsável pelo financiamento eqüitativo, o distrito por práticas de contratação e alocação de recursos e a escola por decisões curriculares e pedagógicas. ${ }^{4}$ Mas, em alguns casos, há escolhas interdistritais em que estudantes podem freqüentar qualquer escola de um Estado, e o distrito, neste caso, perde o seu público cativo. Como eleitores, os pais responsabilizam o Estado; como consumidores, ao escolherem uma escola em particular, eles podem responsabilizar a escola. Mas, no momento em que seus filhos deixam o distrito em que vivem, eles abdicam da responsabilidade eleitoral nesse nível.

Outras propostas, tais como a reestruturação de escolas e as novas formas de gestão escolar, sugerem que o controle, por parte dos clientes, também pode ser promovido com estruturas escolares voltadas à gestão participativa, revisão acessível e processos de apelação, e envolvimento dos pais nas decisões sobre seus próprios filhos.

\section{Gestão Centrada na Escola}

Nos últimos anos, com o aparecimento de pesquisas que sugerem que o controle burocrático, com ênfase em regulamentos padronizados, é contraproducente para criar a educação ideal para a diversidade de estudantes, as propostas de reorganização escolar têm enfatizado a gestão

4 O sistema educacional americano é bastante descentralizado. Os sistemas são estaduais, divididos em distritos escolares locais, com autonomia fiscal, que são responsáveis pela educação desde o jardim da infância até o nível 12. (Nota dos tradutores) Informações em Souza, J. R. L. Financiamento da Educação. São Paulo, 2003. Tese (dout.) FEUSP. 
local da escola ou a "gestão centrada na escola". Essas propostas pressupõem que a maior responsabilidade é em relação aos alunos e seus pais, e que os professores e os outros profissionais da escola devem ser responsabilizados.

A maioria das propostas de "gestão centrada na escola" defende que as decisões sejam compartilhadas entre os professores, os demais membros da equipe escolar, os pais e os alunos. Afirmam que as melhores decisões serão tomadas quando envolverem aqueles que estiverem inseridos no contexto e que tiverem de conviver com essas decisões. Onde há a participação dos pais e estudantes, essas iniciativas introduzem uma forma de controle político que é muito frágil em sistemas escolares grandes e impessoais. Quando é atribuída maior autoridade ao corpo docente das escolas, os mecanismos de controle profissional, os quais visam garantir a competência e o compromisso da equipe, devem ser fortalecidos de tal forma que essa autoridade seja bem utilizada.

Algumas questões se apresentam neste caso: quanta autonomia deve ser dada para o nível das comunidades escolares para que definam e monitorem os processos e resultados de suas escolas? No sentido inverso, em um sistema em que uma grande parte da autoridade é delegada à escola, como fica a responsabilidade dos governos estaduais e dos distritos locais em relação ao tratamento dado aos alunos e a seu desempenho? Uma questão-chave para esse tipo de gestão escolar é se os Estados e distritos devem ser responsabilizados pela regulação de inputs (recursos) ou de resultados (medidas de desempenho).

Wise e Gendler (1989) têm argumentado convincentemente que quando um Estado garante igualdade de recursos financeiros encoraja iniciativas locais, eqüaliza a capacidade de distritos pobres assegurarem um quadro suficiente de professores altamente qualificados e permite que escolas de distritos pobres escolham entre diferentes opções de equipamentos e de propostas curriculares, assim como o fazem os distritos ricos. Quando o Estado regula os resultados por via de testes padronizados, o seu esforço para produzir igualdade na educação acaba degradando a aprendizagem para todos. Individualidade, criatividade e profundidade são perdidas, tudo o que sobra é uniformidade, convencionalidade e trivialidade (p. 36).

No entanto, os Estados precisam avaliar como as escolas estão cumprindo suas responsabilidades em relação aos estudantes. Em alguns casos, essa função de avaliação pode ter melhor resultado se delegada aos distritos locais, às agências de certificação ou a outras instituições com conhecimentos especializados. Independentemente de quem faz a avaliação, entretanto, um problema central é que as medidas usadas para avaliar o progresso dos estudantes e das escolas - e as formas como elas são 
utilizadas no processo decisório - têm efeitos profundos na própria qualidade de educação. Dessa forma, é importante decidir quem escolhe as medidas para avaliar os estudantes e a escola, e se elas são válidas e úteis aos diferentes objetivos a que se destinam.

Uma preocupação diz respeito ao equilíbrio dos diferentes mecanismos de controle ao se buscar mudanças. Se as escolas passarem a se orientar menos por uma regulação hierárquica para definir seus processos, então outras formas de controle devem ser fortalecidas para garantir o bem-estar dos estudantes. Maiores garantias de competência e compromisso da equipe acompanhariam mecanismos de controle profissional mais rígidos. Maiores garantias de voz aos pais e estudantes acompanhariam mecanismos de controle político mais poderosos, envolvendo participação nas decisões da escola. Maiores incentivos ao atendimento dos desejos dos consumidores podem resultar de mecanismos aprimorados de controle de mercado, envolvendo a escolha da escola. O fundamental é buscar a melhor composição de instrumentos para dar suporte ao aprimoramento da escola, o que irá estimular uma educação responsável e comprometida.

Idealmente, cada nível do sistema assumiria a sua parte específica de responsabilidade:

- os Estados teriam a responsabilidade de prover recursos iguais e adequados às escolas e de garantir a aplicação de padrões eqüitativos e de certificação profissional;

- os distritos escolares seriam responsáveis pelas políticas adotadas (incluindo desde os padrões de contratação de pessoal até as exigências burocráticas), pela eqüidade de distribuição dos recursos às escolas e pela criação de processos que as tornem receptivas às necessidades e preocupações dos pais, dos estudantes e da equipe escolar;

- as escolas seriam responsáveis pela distribuição interna de recursos de forma eqüitativa, pela adoção de políticas que reflitam o conhecimento profissional, pelo estabelecimento de meios para a sua equipe manter-se atualizada, pela criação de processos de identificação e solução de problemas que incentivem o aprimoramento contínuo, e pelo comprometimento com as idéias dos pais, estudantes e de sua própria equipe;

- os professores teriam a responsabilidade de identificar e ir ao encontro das necessidades individuais dos estudantes, baseados no conhecimento profissional e em padrões da prática pedagógica, de avaliar continuamente sua própria prática e a de 
seus colegas, de buscar novos conhecimentos e de revisar continuamente suas estratégias para melhor atender às necessidades dos estudantes.

\section{CONCLUSÃO}

Os testes em grande escala, ou outro meio qualquer de coleta de dados, não criam um sistema de controle em si nem garantem a melhoria em escolas urbanas ou não-urbanas. As escolas ou os distritos desenvolvem várias políticas e práticas que podem torná-los mais responsáveis, usando muitas abordagens diferentes, inclusive métodos para a participação de professores e pais no processo decisório, nas regulações burocráticas, nos recursos legais, nas garantias e no suporte para a competência das equipes e opções de escolha. Os dados sobre o progresso dos estudantes e da escola devem informar o sistema para que se tomem decisões responsáveis e problemas sejam corrigidos quando surgirem.

Uma vez que cada instrumento de controle tem diferentes aspectos positivos e negativos e oferece diferentes incentivos, uma combinação cuidadosa de métodos é necessária para desenvolver as escolas em favor de todos os alunos. Apesar de respostas simples serem atraentes, é apenas por meio de um grande esforço com questões profundas sobre quem é responsável, pelo quê e para quem, que a educação, particularmente em escolas urbanas, se tornará verdadeiramente comprometida com estudantes, pais, educadores, políticos e com o público em geral.

\section{O USO DE INDICADORES ESTATÍSTICOS}

\section{A Importância de Indicadores}

Recentemente, em resposta às pressões por melhorias na educação estadunidense, particularmente em áreas urbanas, Estados, distritos e escolas têm atuado rapidamente para implantar sistemas de controle. Embora haja uma pressão generalizada para que as escolas encontrem formas melhores de desempenhar sua função social - a aprendizagem do aluno - ainda são recentes as discussões de como estimular e ao mesmo tempo medir a melhoria das escolas. Um aspecto importante para a questão do controle é definir os tipos de dados sobre o desempenho das escolas e de estudantes que podem ser usados regularmente para informar o público, os educadores, e quem planeja as políticas públicas a respeito das tendências e necessidades educacionais. Enquanto a maioria dos 
educadores e pesquisadores concorda que um sistema de controle requer múltiplos indicadores, há pouco consenso sobre quais seriam esses indicadores e quem seria responsável por defini-los.

Há também discordância sobre como os indicadores deveriam ser usados em um sistema de controle. Algumas propostas sugerem que as medidas de resultados educacionais - como testes padronizados ou médias finais dos alunos - podem ser usadas para "tornar as escolas responsáveis", desencadeando recompensas, sanções ou ações corretivas. O problema é que esse tipo de controle utiliza um número limitado de registros de desempenho para "motivar" as escolas.

Outras propostas sugerem que é preciso uma ampla gama de indicadores para compreender o desempenho das escolas e verificar se os alunos estão se beneficiando de seus estudos. Isso ocorre porque é difícil interpretar medidas de resultados sem considerar informações sobre os estudantes e suas características em conjunto com os processos, as atividades e os recursos escolares. $\mathrm{O}$ aumento ou a diminuição nos escores de alunos nos testes, por exemplo, podem decorrer de variáveis escolares mudanças na prática da escola, na qualidade dos professores ou nos métodos de ensino -, mas também podem resultam de muitos outros fatores, inclusive mudanças na população de estudantes que se submete ao teste.

Além disso, há a questão de se verificar se e como a disponibilidade de dados estatísticos pode fazer com que as escolas recorram a boas práticas, fiquem mais atentas às necessidades de seus clientes, ou seja, se tornem mais responsáveis. Conforme foi comentado na seção anterior, as escolas responsáveis estabelecem políticas e práticas em todas as áreas nas quais provavelmente irão produzir uma educação responsável e comprometida com seus alunos. Os sistemas de controle dessas escolas lhes possibilitam estabelecer objetivos ou critérios e em que medida estão sendo alcançados; as escolas instituem processos pelos quais esses critérios são mais prováveis de serem alcançados ou mantidos, e incluem formas de solucionar problemas quando ocorrem. Enquanto bons indicadores podem ajudar, informar e incrementar as operações escolares, os indicadores per se não possibilitam o controle. De fato, indicadores precários, ou quando são mal usados, podem, na verdade, enfraquecer o controle por se criarem suposições incorretas sobre o que as escolas estão fazendo e o que os estudantes estão aprendendo.

Qualquer que seja a escolha de indicadores, eles são utilizados para possibilitar inferências; por exemplo, se houve queda no desempenho educacional, ou, ainda, como o desempenho dos estudantes norteamericanos em matemática se compara ao dos estudantes de outros países. 
Algumas vezes, em razão do custo, escolhe-se um número pequeno de indicadores por ser simples coletá-los. Preocupações com custo e conveniência podem impedir uma boa avaliação de habilidades cognitivas mais elaboradas, pois esse tipo de avaliação requer tarefas que exigem mais tempo dos estudantes e têm um custo mais elevado. Preocupações similares com custos e eficiência podem, também, impedir a coleta de dados suficientes para testar hipóteses alternativas de tendências observadas. Por exemplo, o escore médio dos testes aumentou em virtude dos cursos mais avançados a que os alunos tiveram acesso, ou devido ao crescimento das taxas de evasão dos estudantes com baixo rendimento? No último caso, um incremento no escore médio dos testes, causado pela exclusão de escores mais baixos, pode ocorrer sem que nenhum estudante tenha, na realidade, melhorado seu desempenho.

Obviamente, é importante para esses sistemas de indicadores que estão sendo desenvolvidos considerar cuidadosamente $o$ que eles querem medir, como eles podem medir melhor e quais outras informações são importantes para interpretar as tendências de forma inteligente. À medida que as escolas isoladas, os distritos escolares e as Secretarias de Educação começam a desenvolver sistemas de controle mais complexos, várias questões concernentes aos indicadores devem ser consideradas.

\section{Critérios para a Escolha de Indicadores}

Os indicadores devem oferecer pelo menos um dos seguintes tipos de informações (Oakes, 1986; Koretz, 1989):

1) Informações orientadas por problemas: os indicadores devem ser capazes de detectar problemas usuais ou alertar os sistemas escolares sobre dificuldades potenciais. Ex: rotatividade do quadro de professores ou mobilidade dos alunos.

2) Informações relevantes para a política educacional: os indicadores não devem descrever apenas as condições de interesse dos legisladores; as condições devem ser descritas de forma a apontarem mudanças que possam ser realizadas com decisões políticas. Por exemplo: se os administradores do sistema de ensino estão interessados em ter mais estudantes em cursos acadêmicos no ensino médio, os indicadores devem fornecer informações sobre quais estudantes e em quais escolas não estão fazendo esses cursos, assim os administradores saberão para onde dirigir seus esforços. 
3) Informações sobre resultados educacionais: esses dados devem incluir as taxas de concluintes e de desistentes; os índices de presença; as medidas de cidadania responsável, tais como índices de participação nos processos eletivos ou em atividades cívicas; ou as medidas de aprendizagem (por exemplo: escores dos testes de desempenho; avaliação do trabalho dos alunos, tais como amostras de textos; avaliação da participação em atividades, como feira de ciências, publicações dos alunos ou jornais escolares, debates, produções teatrais).

4) Informações sobre as origens e a trajetória dos estudantes: os indicadores podem ser mal interpretados quando não se conhecem os estudantes que estão envolvidos nos processos escolares. Por exemplo, se a população estudantil de uma escola apresenta grande mobilidade, os escores de testes podem não estar medindo esses estudantes. Da mesma forma, monitorar as condições de acesso eqüitativo à escola requer o conhecimento dos resultados escolares, associados a diferentes grupos da população estudantil e ao tipo de experiência escolar a que estão expostos.

5) Informações sobre fatores do contexto escolar: alguns dados do contexto escolar, tais como a qualificação de professores ou o uso de certos métodos de ensino que desenvolvem a aquisição de habilidades mais elaboradas, já foram relacionados com os resultados escolares. Entretanto, outros dados precisam ser levados em conta nas informações do sistema, como: recursos financeiros, carga horária dos professores, oferta curricular da escola. São dados necessários para se compreender como o sistema funciona, mesmo que a pesquisa não tenha ainda relacionado todos esses dados diretamente com o desempenho da escola.

\section{Avaliando o Contexto Escolar}

Para que se entenda o que está acontecendo nas escolas, é importante que os indicadores caracterizem os recursos, as pessoas e as atividades que dão forma às experiências dos estudantes. Oakes (1989) afirmou que os indicadores do contexto escolar podem oferecer pistas sobre as causas dos resultados das escolas e impedi-las de não enfatizarem objetivos não mensuráveis, embora importantes, a fim de apresentar resultados que "pareçam bons", segundo as limitadas medidas de 
resultados ora disponíveis. As medidas do contexto escolar permitem que aqueles que usam um sistema de controle desagreguem os dados por gênero, raça e classe social e examinem se há igualdade nas oportunidades educacionais. Elas também permitem desagregações segundo importantes subgrupos, tais como estudantes em cursos acadêmicos ou em cursos técnicos.

Embora os recursos fiscais da escola, e mesmo outros (relativamente fáceis de tabular), sejam um pré-requisito necessário para a boa escolarização, não estão diretamente relacionados com a melhora na aprendizagem do aluno; isso porque práticas organizacionais, como a política de vagas, decisões curriculares e o tempo dedicado à aprendizagem, mediam o uso de recursos (Madaus et al., 1979). Todavia, os recursos influenciam as oportunidades de aprendizagem dos estudantes e assim, definitivamente, afetam seu desempenho. Dessa forma, é importante compreender onde os vários recursos se integram ao amplo esquema de escolarização, para que possam ser construídas medidas úteis.

Trabalhando com uma ampla base de pesquisas educacionais, Oakes (1989) sugere que três variáveis interrelacionadas são importantes para o desempenho escolar e que cada uma delas pode ser examinada com um conjunto de indicadores. A primeira, acesso ao conhecimento, é a gama de oportunidades que as escolas oferecem aos estudantes para que tenham o domínio de vários conhecimentos e habilidades. A segunda, pressão pela melhoria, é uma mistura de oportunidades e incentivos que as escolas provêem aos estudantes para trabalharem com afinco e vencerem. A terceira, condições profissionais de ensino, são os fatores ambientais que podem motivar ou desmotivar professores e administradores na criação e implementação de programas instrucionais. Como é demonstrado no quadro a seguir, pode-se criar um conjunto de indicadores para cada uma das variáveis.

\section{Quadro 1 - Indicadores do Contexto Escolar}

\begin{tabular}{|l|l|l|}
\hline Acesso ao conhecimento & \multicolumn{1}{|c|}{ Pressão pela melhoria } & \multicolumn{1}{c|}{ Condições de ensino } \\
\hline Qualificações dos professores & $\begin{array}{l}\text { Envolvimento administrativo nas questões } \\
\text { pedagógicas }\end{array}$ & Salário dos professores \\
\hline Tempo de aula & Exigências para a conclusão do curso & Quantidade de alunos/Tamanho da classe \\
\hline Cursos oferecidos & Matrículas em programas avançados & Tempo dos professores para planejamento \\
\hline Práticas de grupo & Reconhecimento das realizações acadêmicas & Trabalho no colegiado \\
\hline Materiais, equipamentos & Expectativas acadêmicas & Envolvimento em decisões \\
\hline Métodos de ensino & Qualidade/tipo dos trabalhos de casa & Avaliação enfatizando a aprendizagem \\
\hline Suporte acadêmico & Atividades didáticas ininterruptas & Flexibilidade dos professores \\
\hline Atividades de enriquecimento & & Suporte administrativos para inovações \\
\cline { 1 - 1 } Envolvimento dos pais & & Suporte da secretaria \\
Crença dos professores & & \\
\hline
\end{tabular}


Essas são apenas amostras dos tipos de fatores do contexto escolar que influenciam o desempenho da escola e a aprendizagem dos alunos. Certamente, é necessária uma dose de inventividade para encontrar indicadores apropriados para as características escolares como "condições de ensino" e "pressão pela melhoria". Ademais, nenhum indicador será útil sozinho; um grupo abrangente deve ser extraído de cada uma das várias categorias, isso se o tipo e a qualidade da educação oferecidos pela escola ou pelo sistema de ensino for julgado com seriedade.

Entendendo os benefícios potenciais de um sistema de indicadores mais abrangente, alguns Estados e distritos norte-americanos começaram a coleta de dados como o nível de uso dos recursos fiscais, as qualificações do corpo docente, os cursos oferecidos e os padrões dos cursos feitos pelos estudantes, como também as taxas de aprovação e de evasão e informações sobre a origem dos estudantes (McDonnell, Oakes, 1988).

\section{Critérios para Interpretar Indicadores}

Um dos grandes perigos dos indicadores é a facilidade de serem mal-interpretados - na maioria das vezes porque eles são usados ou interpretados de forma inadequada, dando, assim, impressões falsas. As más-interpretações mais comuns são causadas pelo uso de escores médios dos testes para indicar a qualidade das escolas ou dos distritos escolares.

A maioria das pessoas entende que, uma vez que as escolas atendem estudantes com necessidades educacionais e níveis de conhecimento muito diferentes, o escore médio dos testes dos estudantes, sozinho, não é uma medida válida da qualidade do ensino oferecido. Entretanto, outras pessoas não entendem que até mudanças nos escores de uma escola, de um ano para outro, não captam os efeitos da qualidade da escola. A mini-amostra de dois anos de escores dos testes do Colégio Lincoln 5 , a seguir, sugere como as mudanças nos escores médios podem deturpar o real aproveitamento do aluno.

${ }^{5}$ No original Lincoln Junior High School. (Nota dos tradutores) 


\section{Quadro 2 - Escores dos Testes do Colégio Lincoln}

\begin{tabular}{|c|c|}
\hline $\mathbf{1 9 8 7}$ & $\mathbf{1 9 8 8}$ \\
\hline 10 & 9 \\
\hline 9 & 8 \\
\hline 8 & 7 \\
\hline 7 & 6 \\
\hline 2 & \\
\hline 36 & 30 \\
\hline Média $=7,2$ & Média $=7,5$ \\
\hline
\end{tabular}

Os números representam escores individuais de alunos em um teste aplicado em dois anos consecutivos. Embora o incremento na média dos escores do teste (de 7,2 para 7,5) pudesse sugerir que a escola está melhorando, na verdade, os escores de todos os seus alunos abaixaram. A melhoria ilusória se deve ao fato de que o estudante de mais baixo escore não aparece na lista do segundo ano da avaliação (1988), muito provavelmente porque foi transferido, abandonou o curso ou foi colocado em algum programa de educação especial, no qual o seu escore não é contabilizado. De fato, onde esse tipo de medida é utilizado para avaliar escolas, especialmente quando há muita coisa em jogo, como recompensas ou sanções ligadas ao escores dos testes, são criados incentivos para forçar estudantes com baixos escores a saírem das escolas ou, pelo menos, não serem incluídos na contagem do escore do teste (Darling-Hammond, 1990a; Haney, Madaus, 1986).

Este exemplo ilustra um problema de validade. (Validade e confiabilidade são duas características técnicas relevantes na escolha e no uso de um indicador.)

$A$ validade não é parte integrante da medida, mas se refere à relação entre a medida e as inferências produzidas a partir dela. Se as médias escondem informações individuais dos estudantes, então serão inválidas quaisquer interpretações sobre o progresso da escola ou do aluno a partir dos indicadores baseados em tendências da média de escores dos testes. De forma similar, professores que "ensinam para o teste" podem invalidar as inferências produzidas pelo significado dos escores dos testes. Isso porque os itens dos testes só pretendem ser amostras de domínios da aprendizagem, e a suposição de que o desempenho do aluno nesses itens represente um domínio amplo dos objetivos curriculares é violada quando o foco do ensino é dirigido apenas aos itens que aparecem nos testes (Koretz, 1988). 
A confiabilidade refere-se ao grau em que um indicador está livre de erros aleatórios de medida. Isto é, se é provável que o escore de um estudante em um teste mude significativamente de uma ocasião para outra, ou se as estatísticas sobre as ofertas curriculares de uma escola têm probabilidade de variar, dependendo de quem está coletando os dados.

Os problemas de validade e de confiabilidade levantam algumas preocupações que ameaçam a precisa interpretação dos indicadores.

Corruptibilidade dos Indicadores. Infelizmente, como argumentado anteriormente, é possível mudar uma medida sem causar mudança comparável no construto que essa medida deve medir. Por exemplo, a ênfase em escores de testes de habilidades básicas, como leitura e matemática, tem estimulado o ensino voltado para os testes, o que pode significar que os escores não indiquem, necessariamente, o aproveitamento geral dos alunos, porque os estudantes despendem menos tempo em outras disciplinas, tais como ciências, estudos sociais ou artes (Darling-Hammond, Wise, 1985). Pode também significar que os escores já não sejam expressão de uma avaliação abrangente das habilidades dos alunos, mesmo nas disciplinas testadas. Como a aula se torna estritamente orientada para os testes, alguns aspectos das disciplinas que não são avaliados, como a análise, soluções de problemas complexos e expressão oral e escrita, deixam de ser ministrados.

Não é de surpreender que, nos anos de 1970, enquanto os escores de testes de habilidades básicas dos estudantes dos EUA aumentam, os escores da avaliação de habilidades de pensamento complexas vêm decrescendo de forma constante em virtualmente todas as disciplinas. Técnicos da Avaliação Nacional para o Progresso Educacional, do Conselho Nacional de Pesquisa e dos Conselhos Nacionais dos Professores de Inglês e Matemáticas, entre outros, têm atribuído esse declínio à ênfase escolar nos testes de habilidades básicas.

Como a Avaliação Nacional para o Progresso Educacional (NAEP) afirmou a partir de seus achados: apenas 5\% a 10\% dos estudantes vão além da leitura inicial de um teste; a maioria parece genuinamente confusa diante de pedidos para explicar ou defender seus pontos de vista. Os assessores da NAEP relatam que os métodos correntes de ensino e de leitura de testes requerem respostas curtas e baixo nível cognitivo de pensamento, resultando em uma ênfase em opiniões superficiais às custas de um pensamento racional $e$ disciplinado..., [assim] não é surpresa que os estudantes deixem de desenvolver habilidades de raciocínio e de análise mais abrangentes (NAEP, 1981).

Escores de testes não são os únicos indicadores que podem ser manipulados. Por exemplo, indicadores dos cursos realizados pelo estudantes podem demonstrar sentidos diversos daqueles pretendidos 
pelos administradores dos sistemas de ensino se os cursos forem reclassificados ou modificados para dar-lhes a aparência de que atendem aos requisitos exigidos. Quando a pressão é grande para atender a novos padrões, as escolas com poucos recursos ou escassez de professores qualificados podem implementar novos requisitos, em matemática ou em ciências, bem diferentes dos de escolas ricas com estudantes de alto nível de desempenho. Por um lado, três anos de curso de ciências podem significar três anos de aulas reclassificadas como de ciências gerais; por outro, podem significar um completo e rigoroso programa de biologia, química e física, repleto de experiências laboratoriais. Quando um indicador tem diferentes significados em situações diversas, ele apresenta problemas, tanto de confiabilidade como de validade, e não pode ser interpretado adequadamente.

Certamente, para um sistema de indicadores funcionar todos os seus participantes - inclusive aqueles que estão apenas coletando os dados - devem entendê-lo como a serviço de seus interesses e necessidades. Como um sistema de indicadores representa uma ameaça, por exemplo, à aprovação dos estudantes, à obtenção de fundos, ou à segurança no emprego dos profissionais da escola, ou oferece a possibilidade de uma recompensa, as informações que o alimentam são passíveis de corrupção. Uma vez que os indicadores refletem situações de risco, as medidas dos objetivos reais são parciais, e os objetivos não-mensuráveis do sistema tendem a ser sacrificados (Haney, Madaus, 1986).

Propósitos do Sistema de Indicadores. Cada sistema de indicadores necessariamente tem $\mathrm{o} / \mathrm{s}$ seus/s foco/s. Contudo, os indicadores também devem ser abrangentes o suficiente para captar os efeitos colaterais não intencionais. Por outro lado, as formas pelas quais as políticas afetam o sistema educacional podem passar despercebidas, e podem ser produzidas inferências incorretas sobre o que está realmente ocorrendo (Koretz, 1989).

Por exemplo, se um Estado ou distrito não tem professores suficientes de língua estrangeira, a política planejada para incrementar as matrículas em Espanhol Básico pode provocar a queda do número de cursos de Espanhol Avançado oferecidos, na medida em que professores são desviados de um curso para outro. De forma semelhante, como o espaço no currículo é limitado, a menos que se aumente o tempo de escolarização, quando apenas alguns aspectos são ajustados, mais ênfase em uma disciplina pode representar menos em outra. Um aumento nos requisitos de ciências pode resultar em alunos cursando menos disciplinas de história. Um aumento dos requisitos para a conclusão do curso pode estimular alguns alunos a cursarem mais disciplinas, mas pode aumentar a chance de outros abandonarem o curso. 
Se um sistema de indicadores for abrangente, incluirá medidas dos vários aspectos do sistema educacional: recursos e ofertas escolares, disponibilidade e qualificação dos professores, participação e desempenho do aluno. Isso permite monitorar os efeitos colaterais não intencionais e realizar mudanças apropriadas para alcançar os objetivos genuínos das políticas.

Fazendo comparações justas. Sistemas de controle em geral envolvem comparação entre escolas e distritos. Mais que isso, recompensas e sanções são cada vez mais associadas a bons ou maus resultados nessas comparações. Assim, é importante que essas comparações sejam organizadas de forma justa. Isso significa que os resultados da escola não podem ser comparados sem também se comparar as populações (e populações mudam o tempo todo), os recursos e até os objetivos educacionais.

Uma forma de fazer comparações justas é desenvolver medidas longitudinais do progresso do estudante - medidas referenciadas a critérios de quanto cada aluno aprendeu ao longo de um período de tempo - como base para agregar os escores recebidos pelos estudantes, por escola. Esta abordagem, utilizada com limitações em algumas escolas de Nova York, examina com maior precisão o progresso dos alunos do que a prática padronizada de comparação de escores de escolas com populações estudantis muito diferentes, ou, ainda, a prática de observar as mudanças nas médias dos escores dos testes (por exemplo, de dois grupos diferentes de estudantes do terceiro ano em dois momentos distintos), particularmente em escolas com altos níveis de mobilidade estudantil.

Uma outra estratégia é comparar escolas com escolas "semelhantes". O Estado da Califórnia, por exemplo, provê cada escola com um detalhado relatório comparando-a com escolas com grupos de estudantes similares numa amplo rol de indicadores. Esses indicadores incluem a taxa de participação do aluno em cursos acadêmicos, de freqüência e de evasão, atitudes sociais e percepções em relação à escola, e dados de mobilidade e informações dos escores dos testes, desagregados por grupos de renda (Archbald, Newman, 1988).

A abordagem da Califórnia, embora não seja perfeita, representa uma melhoria marcante em relação à estratégia estatística, a qual tem, algumas vezes, sido usada para "ajustar" os escores dos testes escolares, com base nas características dos sujeitos. Infelizmente, essas fórmulas de "ajuste" técnico reificam os efeitos das práticas escolares discriminatórias pelo obscurecimento de diferenças nos recursos das escolas de baixa-renda e de atendimento a minorias, diferenças que deveriam ser destacadas se se desejasse promover comparações para um verdadeiro controle. 
Um exemplo de como os indicadores comparativos podem ser usados para ocultar ou destacar fatores que influenciam no desenvolvimento escolar pode ser visto no caso da aprendizagem de matemática. Dados de muitas fontes têm mostrado um desenvolvimento distinto em matemática entre estudantes de minorias não-asiáticas e estudantes brancos. No entanto, indicadores comparativos têm demonstrado, apenas recentemente, que cursar matemática - decisão fortemente relacionada aos escores dos testes de desempenho - é um fator que varia substancialmente conforme o grupo racial/étnico. Na realidade, para estudantes com registros similares de opções de cursos, as diferenças dos escores dos testes de desempenho por raça ou etnia, virtualmente desaparecem (Oakes, 1989).

As desigualdades nas opções de cursos são devidas, principalmente, ao fato de que escolas que recebem estudantes advindos de grupos de minorias, de baixa-renda e moradores de regiões com problemas socioeconômicos mais graves, têm bem poucos professores qualificados e oferecem uma quantidade bem menor de cursos avançados do que as escolas que não recebem esse público (Oakes et al., 1990; DarlingHammond, 1990b). As comparações de escores de testes que ignoram esses fatores têm poucas chances de direcionar a atenção dos administradores dos sistemas de ensino para retificarem as verdadeiras fontes dos problemas.

\section{Indicadores e Política}

Embora os indicadores não forneçam o texto, eles fornecem subsídios para a política e são poderosas ferramentas. De um lado, os indicadores podem influenciar a opinião pública a favor de políticas que podem ser educacionalmente benéficas - tais como a contratação de um número maior de professores de matemática bem qualificados no sentido de garantir um rico currículo de matemática para todos os estudantes. De outro, podem persuadir o público, de forma indireta, a endossar políticas que são educacionalmente perigosas - tais como escores de testes como base para a promoção de estudantes para as séries seguintes ${ }^{6}$.

Mais diretamente, os indicadores estão sendo cada vez mais usados para avaliar os professores e julgar as escolas e, em geral, como um "fator

\footnotetext{
${ }^{6}$ Enquanto um recente levantamento descobriu que $3 / 4$ do público é favorável aos testes como um pré-requisito para a aprovação e conclusão de curso (Departamento de Educação dos Estados Unidos da América, 1987), outra pesquisa demonstrou que os estudantes que eram retidos aprendiam menos e tinham maior probabilidade de abandonar o curso do que estudantes com níveis de escolaridade semelhantes que eram promovidos (Holmes, Matthews, 1984; Carnegie Council on Adolescent Development, 1989).
} 
de ansiedade" para gerar melhoria nas escolas. Algumas das conseqüências do mau uso de medidas específicas, como ferramentas para provocar mudanças nas escolas, já foram comentadas anteriormente. Onde recompensas e sanções são determinadas automaticamente, pelo aumento ou diminuição de medidas restritas, os efeitos colaterais são ainda mais danosos, uma vez que estudantes com baixo desempenho podem ser expulsos e profissionais talentosos podem rejeitar cargos em escolas que atendem crianças com necessidades educacionais mais desafiadoras.

Sob essas condições, os indicadores parecem subestimar, em vez de contribuir para um controle genuíno, pois são usados para furtar-se à responsabilidade de uma análise cuidadosa e de complexos processos de tomada de decisões em favor das simplistas, embora perigosas, "curas". Se os administradores dos sistemas de ensino e educadores devem ter o encargo de atender aos alunos de maneira responsável e comprometida, necessitam usar as informações sobre as condições educacionais em conjunto com o conhecimento de práticas educacionais saudáveis para avaliar onde se justificam mudanças e para adotar estratégias que darão suporte ao sucesso estudantil.

Finalmente, os indicadores devem ser vistos como um conjunto de dados num processo de "construção política reflexiva" e como um auxílio para um processo reflexivo de tomada de decisões nas escolas. Devem ajudar a identificar áreas que demandam investigações mais aprofundadas e fornecer pistas para linhas de trabalho mais promissoras.

\section{Quem deve Escolher os Indicadores?}

Qualquer sistema de controle na educação contém não apenas indicadores, mas mecanismos que tornam certos indivíduos (professores, diretores, etc.) responsáveis por outros. Até agora, a tendência tem sido a de construir sistemas de controle de cima para baixo. Os mais recentes sistemas de indicadores têm sido, na maioria, definidos pelos Estados norte-americanos e têm ajudado a consolidar uma autoridade na tomada de decisões nesses Estados. Muitas vezes, distritos escolares tiveram de modificar as prioridades curriculares a fim de atuar de acordo com os sistemas de indicadores dos Estados. $\mathrm{O}$ resultado tem algumas vezes desestimulado os tipos de aprendizagem que eram valorizados nas comunidades locais. Dessa forma, uma das vantagens, assim como um dos perigos de um sistema de indicadores é que, ao mesmo tempo em que pode produzir uma educação mais responsável para aqueles que escolheram os 
indicadores, pode também diminuir a sensibilidade do sistema para outros.

A fim de atender aos pais e às necessidades individuais dos alunos, as escolas locais freqüentemente precisam coletar informações que são bastante diferentes daquelas exigidas pelo Estado. Essas informações são úteis para decidir o que está funcionando ou o que está falhando em determinada escola, em determinado curso acadêmico, ou em certa sala de aula. Como as pesquisas sobre melhorias nas escolas têm demonstrado a importância de suas dependências como locus de mudança (Oakes, 1989), convém ressaltar que os indicadores locais podem provar ser educacionalmente mais eficazes (veja a seção a seguir).

Em virtude do controle nos níveis estadual e nacional, é fácil esquecer que ambos os níveis de governo estão apenas agindo em nome dos pais dos alunos e de outros cidadãos. Assim, independentemente de onde são instituídos, os indicadores devem fornecer informações reais e compreensíveis sobre a qualidade da educação oferecida. Como os pais podem reagir a uma informação de indicador, matriculando ou retirando seus filhos de uma escola, é importante que essa informação seja a mais rica possível - sem, obviamente, distorcer o que está acontecendo em uma escola, em particular, ou em um distrito escolar.

\section{CONCLUSÃO}

Administradores dos sistemas de ensino estão apenas começando a ir além dos indicadores ainda rudimentares de resultados, como os escores dos testes dos estudantes, para compreender os recursos e as atividades escolares. Essa noção ampliada de indicador é essencial para qualquer inferência sobre o significado dos resultados escolares.

O desenvolvimento de indicadores do contexto escolar é particularmente importante e é preciso algum esforço para identificar os formatos apropriados para extrair as informações necessárias. Um ponto importante de se ter em mente é que o contexto escolar somente pode ser inferido por múltiplos indicadores que, simultaneamente, cobrem áreas como acesso ao conhecimento, pressão pela melhoria e condições profissionais de ensino.

Quer os indicadores focalizem os inputs ou os resultados, deve-se tomar cuidado para proteger a qualidade técnica dos dados, criar um nível de análise que isole importantes diferenças internas da escola no que se refere às oportunidades de aprendizagem, bem como para assegurar que as comparações interescolares sejam justas. É também importante exercer 
vigilância contínua sobre a corruptibilidade dos indicadores, de sorte que não sejam usados para obscurecer a realidade do que as escolas estão oferecendo e para quem.

Enquanto os indicadores pretendem monitorar a qualidade ou o status de um sistema de ensino, com o intuito de fornecer informações para a política educacional, suas implicações políticas podem ser facilmente superestimadas. Os indicadores não podem fornecer as informações especificamente projetadas e detalhadas, que são necessárias para responder questões fundamentais de pesquisa ou avaliar determinadas políticas e programas, nem podem definir o que se entende por educação boa ou legislação educacional desejável.

Finalmente, os indicadores não são um substituto nem para idéias educacionais nem para decisões sobre quais políticas devem ser implementadas. Estas serão sempre influenciadas por valores assim como pelo conhecimento. Como Oakes (1986) escreveu: os indicadores não podem remover decisões fundamentais sobre a escolarização do processo político - da reflexão e do debate entre administradores dos sistemas de ensino e o público, em última instância responsável pelo seu funcionamento saudável (p. 23).

\section{CRIANDO SISTEMAS DE CONTROLE NO NÍVEL ESCOLAR}

\section{O Papel dos Testes}

Na busca do controle tem havido uma tendência de se enxergar os testes como uma das principais formas de medida e como uma ferramenta em prol de mudanças. Infelizmente, os testes não garantem que as escolas ensinem bem ou de forma responsável, ou mesmo que os estudantes aprendam o que seus pais e a sociedade desejam que eles aprendam. Dois relevantes estudos recentes sobre a educação estadunidense chamam a atenção para a degradação da aprendizagem que vem na esteira do crescimento dos testes padronizados. O trabalho de Ernest Boyer (1983), sobre as escolas de ensino médio nos EUA, encontrou uma superabundância de práticas de ensino, consistindo da transmissão de fragmentos de informações, não-examinadas e não-analisadas. Boyer observou:

A pressão está no desenvolvimento de habilidades que podem ser contabilizadas e relatadas. Como um professor disse: "Estamos tão compenetrados em informar ganhos mensuráveis para a comunidade através dos testes padronizados nacionais, que ignoramos o ensino daquelas áreas em que isso não pode ser feito". 
Da mesma forma, John Goodlad (1984) descobriu, em seu vasto estudo de mais de mil salas de aula nos EUA, que a maioria dos estudantes ouvem, lêem pequenos textos nos livros didáticos, dão respostas breves a perguntas e resolvem questões de múltipla escolha ou que exigem respostas curtas. Mas raramente planejam ou tomam uma iniciativa, criam seus próprios materiais, lêem ou escrevem algo substancial, ou se envolvem em discussões analíticas. E há pouco incentivo para que seus professores tentem alcançar esses objetivos. Goodlad (1984) comenta:

Os professores são sensiveis às pressões que os programas de testes padronizados dos Estados e dos distritos fazem sobre eles. Eles entendem a mensagem. As outras mensagens que há objetivos além daqueles que os testes medem, que a busca desses objetivos reclama estratégias de ensino alternativas, que os aspectos fundamentais do currículo transcendem as exigências de cada grau - são fracas, e são abafadas pela mais imediata e forte mensagem...

Esses estudos mostram como é importante que as escolas escolham cuidadosamente suas "ferramentas de controle". Se as medidas de desempenho devem, na realidade, ser utilizadas para embasar um controle significativo, precisam avaliar e encorajar formas valorizadas de aprendizagem dos alunos. Além disso, para que tais ferramentas sejam úteis no âmbito escolar, necessitam mostrar como os estudantes estão progredindo individualmente, e devem ser acompanhadas por métodos que salientem como realizar mudanças na prática para melhorar a aprendizagem do aluno.

\section{Criando um Sistema de Controle}

Como pôde ser percebido na primeira seção, um sistema de controle é um conjunto de compromissos, políticas e práticas projetadas para criar e fomentar boas práticas e uma auto-avaliação contínua.

Assim, os critérios adotados pelas escolas para contratar, organizar e avaliar o seu grupo de profissionais são parte de um genuíno sistema de controle. Também o são os critérios usados para estruturar o ensino e a aprendizagem; tomar decisões sobre os currículos; desenvolver políticas sobre a organização de turmas, a aprovação e a disciplina dos estudantes; criar mecanismos de comunicação entre e com professores, estudantes e pais para resolver problemas que surjam; e criar meios para avaliar como as crianças, individualmente, e a escola, como um todo, estão se desenvolvendo. 
As escolas diferem tanto na responsabilidade de suas práticas educacionais como na resposta às necessidades e opiniões dos estudantes, pais e profissionais que nelas atuam. Por exemplo, uma escola que tem cuidado com a contratação e apóia profissionais competentes e comprometidos é mais responsável do que outra que contrata professores sem levar em consideração sua capacidade ou não oferece condições para que ministrem suas aulas com competência. Uma escola que provê muitas ocasiões para que o seu grupo de professores se reúna e se encontre também com os pais para avaliar e discutir o seu trabalho e o progresso dos alunos é mais responsável do que outra que não cria oportunidades para que os pais e a escola se envolvam na resolução de problemas que visem a promover melhores estratégias pedagógicas. Uma escola que dá atenção às necessidades individuais de seus alunos (e procura se preparar, por iniciativa própria, para satisfazer essas necessidades) é mais responsável do que outra que trata os estudantes em massa, permitindo que muitos sejam reprovados.

A questão central é que o controle é alcançado apenas se a política e a prática escolares contribuírem tanto para uma boa educação como para a solução de problemas quando eles ocorrerem. Os indicadores de desempenho e os contínuos processos de diagnóstico são ferramentas necessárias para avaliar se essas condições estão sendo cumpridas. Esses processos incluem momentos para avaliar como a escola está funcionando e quão bem estão sendo atendidas as necessidades dos alunos. Incluem também métodos para mudar práticas escolares - até mesmo reestruturar certos aspectos da organização escolar - se elas não forem ideais para os alunos.

\section{Trabalhando com Diferentes Níveis de Controle}

Todas as escolas são diferentes. Nenhuma estrutura administrativa imposta de cima para baixo pode servir completamente às necessidades específicas de professores e alunos em uma situação particular (Lieberman, Miller, 1990). Enquanto informações coletadas e analisadas de forma centralizada podem, algumas vezes, ser úteis a uma escola para identificar questões que demandam um exame mais minucioso, as estratégias de melhoria da escola devem ser baseadas em objetivos, questões, problemas e processos de mudança locais, assim como em informações bem detalhadas e de relevância imediata. Para reconhecer as qualidades particulares e para analisar os desafios especiais de uma escola, ela deve elaborar suas próprias estruturas de controle. 
Infelizmente, sistemas de controle impostos de cima para baixo que consomem bastante o tempo e os recursos das escolas, podem, às vezes, desencorajá-las a trabalhar para alcançar seus próprios sistemas de controle. No entanto, se as próprias escolas não trabalharem para criar práticas mais responsáveis e comprometidas, elementos externos à escola certamente irão ocupar esse espaço, até com abordagens mais intrusivas que provavelmente demonstrarão menos sensibilidade em relação ao contexto escolar e uma inadequada avaliação do potencial da escola e de seus recursos humanos - professores, pais e estudantes.

Em última instância, cada segmento do sistema deve assumir sua parte de responsabilidade:

- O Estado e a secretaria da educação devem ser responsáveis pelas políticas que adotam, assegurando que seus processos decisórios contem com os melhores conhecimentos disponíveis e com os interesses das crianças, e avaliem os subseqüentes efeitos das políticas no ensino e na aprendizagem, na possibilidade de acesso dos estudantes, no tempo de ensino, na extensão da burocracia criada etc. Devem assumir responsabilidade pela eqüidade na distribuição dos recursos escolares e na criação de processos que os tornem comprometidos em atender às necessidades e preocupações dos pais, estudantes e da equipe de profissionais da escola.

- A escola deve ser responsável pela adoção de políticas que reflitam o conhecimento profissional e os interesses das crianças, pela eqüidade na distribuição de oportunidades de aprendizagem às crianças, pelo estabelecimento de meios que permitam a seus profissionais um aprendizado contínuo e o aprimoramento de suas habilidades, pela criação de processos de comunicação, pela identificação e solução de problemas, e pela criação de métodos que envolvam e respondam às preocupações e idéias dos pais, dos estudantes e dos profissionais.

- Professores e demais profissionais da escola devem ser responsáveis por identificar e satisfazer as necessidades individuais dos estudantes a partir de conhecimentos baseados em padrões profissionais de prática, pela avaliação contínua de quão bem suas práticas estão atingindo essas metas, pela busca de novos conhecimentos e informações, e pela contínua revisão de suas estratégias, procurando um melhor atendimento das necessidades dos alunos. 
Um sistema de controle ajuda todos os envolvidos a fazer seu trabalho de forma mais responsável, por meio da disponibilização de informações sobre as práticas escolares e seus resultados, juntamente com momentos para aprendizagem, aconselhamento e solução de problemas.

\section{Criando Processos que Aprimoram o Controle na Escola}

Profissionais são obrigados a fazer o que for melhor para seus clientes, baseados no melhor conhecimento que tiverem nas suas áreas. Assim, no âmbito escolar, onde a educação de qualidade é definida como o atendimento das necessidades individuais dos estudantes, indiscutivelmente a forma mais importante de controle é o controle profissional.

O controle profissional busca apoiar práticas que são centradas nos estudantes e baseadas no conhecimento. Essa forma de controle está focada em estratégias que pretendem assegurar que:

1) todos os indivíduos inseridos na prática profissional sejam competentes e responsáveis;

2) onde houver conhecimentos sobre práticas apropriadas, ele é usado em tomadas de decisão;

3) onde não houver certeza sobre a prática (ou sobre a melhor solução para a necessidade de um estudante, em particular, ou para um problema), técnicos - individual ou coletivamente, por investigação e consulta - busquem sempre a ação mais responsável.

Ao contrário do controle burocrático, que apenas assegura procedimentos uniformes, o controle profissional busca garantir um processo decisório responsável. Ele muda as regulamentações que determinam o que deve ser ensinado, quando e como, investindo mais na competência do professor. Esses investimentos são feitos por meio de $X$ formas rigorosas e significativas de educação, certificação, seleção e avaliação, juntamente com oportunidades permanentes para aprendizagem, investigação compartilhada e aconselhamento (DarlingHammond, 1990c). Uma estratégia de controle profissional é necessária na educação porque a complexidade do ensino e da aprendizagem demanda que os educadores possam tomar decisões difíceis sobre as necessidades especiais individuais e infinitamente variáveis dos estudantes.

Para criar controle profissional, um sistema deve dar atenção especial: 
- às políticas de pessoal que regem a contratação, designação e avaliação dos professores e demais profissionais da educação;

- às oportunidades para o desenvolvimento profissional, investigação compartilhada e aconselhamento sobre problemas da prática (meios para incentivar o uso do conhecimento profissional além daquele baseado nas experiências individuais dos professores);

- aos mecanismos de avaliação contínua das práticas de sala de aula e da escola, bem como do progresso dos estudantes;

- à criação de incentivos para apoiar a aprendizagem dos professores e demais profissionais da escola, à auto-avaliação e a disposição para aceitar os desafios do ensino e da liderança na sala de aula e na escola.

Resolver problemas coletivamente é o segundo aspecto mais importante do controle escolar. Refere-se ao esforço para estabelecer uma investigação ética e um compromisso de identificar, analisar e lidar com assuntos ou problemas que possam impedir o progresso dos estudantes ou da escola. Tal ethos deve ser apoiado por métodos que avaliem constantemente o que está acontecendo, perguntando não apenas o que está ocorrendo, mas também por que está acontecendo, e se as práticas existentes estão alcançando o que a comunidade escolar pretende. Essas questões não devem ser levantadas apenas uma ou duas vezes ao ano, quando os estudantes são testados ou quando são definidas as necessidades da escola. Em vez disso, elas devem ser levantadas na reunião de professores, no momento em que professores e alunos estão se esforçando para atingir suas metas, e quando ocorra uma avaliação.

Em algumas escolas, esse tipo de questionamento e reflexão coletivos é freqüente. No entanto, o isolamento de professores tem trabalhado contra o controle coletivo, enquanto a centralização do planejamento, da tomada de decisões e da avaliação têm freqüentemente eliminado as oportunidades e os incentivos para esse tipo de atividade na escola.

Entretanto, se as escolas devem se tornar mais responsáveis e abertas a mudanças, elas precisam encontrar caminhos - como outras organizações profissionais têm feito - para que a avaliação faça parte das suas atividades cotidianas. Assim como os hospitais têm comissões permanentes de pessoal, que se reúnem regularmente para discutir a eficácia de vários aspectos do funcionamento hospitalar (cirurgia, patologia, epidemiologia etc.), as escolas também devem instituir momentos regulares para examinar suas práticas. Da mesma forma como os advogados, médicos, psicólogos, assistentes sociais e outros profissionais 
utilizam reuniões de discussão de casos e outras formas de aconselhamento como oportunidades para compartilhar conhecimentos e resolver problemas de seus clientes, os professores também devem ter oportunidade de aproveitar os conhecimentos e as perspectivas de seus colegas em benefício dos seus alunos.

O primeiro tipo de avaliação - envolvimento dos professores em uma revisão atenta da prática dos seus pares - pode ser feito de várias formas. Comissões permanentes, como as de hospitais, podem reunir-se regularmente para rever práticas em diferentes áreas - relações pais-escola, políticas de atribuição de notas e de aprovação, progresso acadêmico, a qualidade de determinados programas ou currículos, a organização da instrução e assim por diante. Comissões ad hoc podem ser formadas para trabalhar em assuntos especiais. Reuniões de professores seriam usadas para investigar estratégias curriculares e outros assuntos departamentais, interdepartamentais, peculiares a um determinado grau de ensino ou comum a todos os graus. Essas atividades regulares de avaliação oferecem oportunidades para o uso de dados avaliativos e de outras informações que possam embasar o processo decisório.

A criação de estruturas de aconselhamento fornece um segundo mecanismo de controle e podem incluir oportunidades para os professores reverem o progresso individual de um aluno ou para avaliações coletivas, a fim de ajudar os estudantes em suas dificuldades. Elas podem também incluir o planejamento coletivo de equipes docentes com o intuito de incentivar as relações profissionais entre professores que apóiam o aconselhamento sobre assuntos curriculares, métodos de ensino e problemas da prática.

A Escola Central Park East, uma escola elementar de Nova York, utiliza tanto a avaliação das práticas de seus pares como mecanismo de consulta coletiva para assegurar que as preocupações da escola e dos estudantes sejam continuamente trazidas à baila e que reine um clima colaborativo na solução de problemas. Entre outras atividades, a equipe de profissionais tem duas reuniões semanais diferentes para este propósito. Uma reunião é utilizada para a análise da situação de um aluno ou para discussão sobre o currículo. No primeiro caso, um professor discute o status de um estudante em particular, e os demais professores acrescentam suas observações sobre a criança, sobre estratégias de ensino ou abordagens interpessoais que possam ser úteis, e sobre pesquisas ou experiências que dizem respeito a algum dos assuntos levantados. O processo enriquece a compreensão de todos, tanto sobre a criança em particular quanto sobre o ensino em geral. A reunião de revisão curricular utiliza uma estratégia similar para examinar um problema específico do currículo. 
A outra reunião semanal trata de assuntos gerais da escola, como as questões concernentes a uma educação multicultural, às relações paisescola ou à avaliação escolar. Como no caso da avaliação dos estudantes ou do currículo, observações da equipe de professores, informações coletadas nas salas de aula, na escola, ou provenientes das famílias, e fragmentos de dados avaliativos (provenientes dos estudantes, da sala de aula ou da escola) podem fundamentar certos aspectos da discussão. Esses e outros processos ajudam os membros da comunidade escolar a assumir a responsabilidade pelo bem-estar dos estudantes e pela vida da escola. Eles promovem um controle genuíno pela criação de um mecanismo de permanente reflexão, avaliação e mudança.

\section{Criando Índices que Aprimoram o Controle da Escola}

Para apoiar os esforços de avaliação da escola, um sistema de indicadores no âmbito escolar deve fornecer informações úteis sobre o contexto escolar, isto é, o que a escola está fazendo e o como os estudantes estão se saindo.

Medidas da aprendizagem estudantil. Como medidas dos "resultados", os testes padronizados mais divulgados comercialmente não são sensíveis às diferenças oferecidas pelos currículos e realmente não avaliam as oportunidades de aprendizagem dos estudantes nas diversas classes e escolas (Madaus et al., 1979). Para extrair uma medida melhor da eficácia escolar há outras opções. Mais convencionais são os testes baseados no currículo, construídos por alguns Estados e distritos escolares, os quais refletem, de forma mais precisa, as metas curriculares e as variações do ensino nas escolas (Madaus et al., 1979).

Além disso, algumas opções menos tradicionais também estão sendo desenvolvidas, incluindo portfólios, exposições, demonstrações e outras avaliações baseadas no desempenho. Contrapondo-se aos testes padronizados de múltipla escolha, essas estratégias de avaliação apresentam problemas de estrutura defeituosa, o que exige dos estudantes um raciocínio analítico e uma demonstração de sua proficiência como se estivessem em uma situação problemática da vida real.

À semelhança dos tipos de avaliação que prevalecem em muitos outros países (onde testes de múltipla escolha não têm muita popularidade), essas abordagens incluem defesas de monografias, projetos de pesquisa, experimentos científicos, apresentações orais e desempenho em áreas como debates e artes. Incluem também portfólios dos melhores trabalhos dos estudantes em várias áreas e projetos em grupo que 
requerem análises, pesquisa, experimentações, cooperação e apresentação escrita, oral ou gráfica das suas conclusões. Freqüentemente, os momentos de avaliação exigem que os estudantes respondam a questões de colegas ou de examinadores externos, ajudando-os, assim, a aprender a refletir e a defender seus pontos de vista (Coalition of Essential Schools, 1990; Archbald, Newman, 1988).

Além de ajudar os professores e os próprios estudantes a avaliarem o que esses são realmente capazes de fazer, essas abordagens servem como ferramentas expressivas e são altamente motivadoras. Sizer aponta que elas funcionam tanto como inspiração quanto como medidas: dar às crianças um bom objetivo real é o melhor jeito de ensiná-las... E se a meta é lançada de um modo interessante, você incrementa, enormemente, as chances de elas a alcançarem (Coalition of Essential Schools, 1990, p. 1).

Algumas escolas, como aquelas na Coalition of Essential Schools ${ }^{7}$, estão empenhadas na criação de avaliações autênticas da aprendizagem estudantil. Além disso, Estados como Vermont, Califórnia, Connecticut e Nova York estão começando a experimentar novas formas de avaliação. Vermont está desenvolvendo portfólios dos alunos como base para seu sistema estadual de avaliação. Connecticut e Nova York iniciaram o desenvolvimento de avaliações baseadas no desempenho, as quais requerem que estudantes realizem um experimento científico ou resolvam um problema da vida real usando conceitos científicos e matemáticos em vez de responderem a testes de múltipla escolha. Maryland desenvolveu uma avaliação escrita que envolve os estudantes em complexas tarefas de escrita, algumas vezes utilizando vários dias de trabalho, incluindo revisões, como parte do processo de avaliação. Municípios como Shoreman-Wading River, no Estado de Nova York; Pittsburg, no Estado da Pennsylvania; e Albuquerque, no Estado do Novo México, também estão criando avaliações fidedignas para substituir os testes padronizados. Um Consórcio de Distritos de Escolas Urbanas, recentemente criado pela Federação Americana de Professores, tem uma lista vasta e crescente de membros que estão colaborando no desenvolvimento de avaliações de desempenho. Uma força tarefa federal especial foi convocada para examinar alternativas aos testes-padrão dos programas de educação compensatória Chapter $1^{8}$.

Sem dúvida, os testes de desempenho ainda precisam lidar com problemas de testes padronizados que foram enfrentados pelas gerações anteriores. Primeiro, embora estudos tenham demonstrado que os

7 Organização não-governamental que visa a apoiar a melhoria da escola elementar e secundária. (Nota dos tradutores)

8 Programa americano de financiamento da educação de crianças provenientes de famílias pobres com desvantagens educacionais. (Nota dos tradutores) 
avaliadores podem chegar a um alto grau de concordância sobre textos e portfólios, os problemas de preconceito cultural, que também se manifestam nos testes padronizados atuais, continuam sem solução. De fato, há indicações que estudantes de minorias podem demonstrar melhor rendimento em alguns tipos de testes de desempenho e pior em outros, dependendo de como as tarefas foram selecionadas e dos critérios e processos de atribuição de nota. Segundo, o tempo e o treinamento necessários para corrigir testes de desempenho certamente parecerão menos eficientes quando comparados aos 10 mil testes corrigidos automaticamente por hora que o Educational Testing Service (ETS) consegue alcançar. Estados e distritos escolares sem muitos recursos podem ter dificuldade em optar por testes de desempenho até que seus benefícios justifiquem os custos. Terceiro, a despeito de esses testes estarem sendo recomendados para enriquecer o ensino e a aprendizagem, a pressão de qualquer programa em que haja muita coisa em jogo pode se voltar contra esses objetivos. Dependendo da natureza das tarefas avaliativas, algumas evidências sugerem que a instrução pode ser dirigida de forma perfeitamente adequada ao formato ou conteúdo de avaliações de desempenho, exatamente como outros testes (Ascher, 1990). Para cumprir sua promessa, as avaliações de desempenho terão de ser construídas de modo a verificar uma vasta gama de habilidades analíticas e capacidades conceituais elevadas, assim como capacidades desenvolvidas de desempenho de forma que o ensino para esses aspectos somente pode ser alcançado se forem mantidos objetivos amplos e enriquecedores para a aprendizagem do estudante.

Independentemente de quais instrumentos de avaliação as escolas tenham de usar atualmente para cumprir requisitos estaduais ou federais, a equipe local das escolas deveria examinar como podem ser genuinamente mais responsáveis por uma aprendizagem valorizada do aluno. Isso pode ser feito criando-se meios de verificar o que os estudantes são de fato capazes de fazer: demonstrações de domínio de um assunto que vão ao encontro dos desejos de realização dos estudantes e de sua vontade de demonstrar sua competência, assim como dos objetivos a longo prazo que a comunidade almeja para seus estudantes.

Medidas da performance escolar. Para informar o processo decisório da escola e para aprimorar as práticas, as avaliações sobre o que os estudantes estão aprendendo devem ser acompanhadas de avaliações sobre o que a escola está fazendo. Na seção anterior, foram discutidas algumas variáveis importantes para a eficácia da escola. Elas incluem características que controlam o acesso dos estudantes ao conhecimento, a pressão escolar pelo bom desempenho e as condições profissionais de ensino. Com criatividade, 
um conjunto de indicadores pode ser constituído para cada uma delas. Por exemplo, a pressão pelo bom desempenho pode ser verificada por medidas concernentes à proporção de estudantes inscritos em programas avançados, o reconhecimento pela escola de realizações acadêmicas, em que medida o tempo para o ensino e a aprendizagem está a salvo de interrupções e fragmentações, e a qualidade e o tipo de tarefa de casa atribuída nas várias classes. Usar um certo número desses indicadores para cada uma dessas três áreas é uma boa maneira de começar a avaliar a qualidade da educação proporcionada por uma determinada escola.

Os indicadores escolares devem levar em conta o ambiente escolar de forma holística, descrevendo a qualidade das experiências escolares das crianças. Os indicadores podem consistir de observações sistemáticas por parte dos professores acerca do comportamento do aluno ou da sala de aula e de práticas escolares; informações de questionários, entrevistas ou debates com alunos, pais ou profissionais da escola; contagem de eventos específicos ou agregação de dados; e avaliações estruturadas do desempenho da escola ou dos alunos.

Os indicadores do desempenho da escola devem sempre começar com questões acerca de como os estudantes estão se saindo: sua participação e ligação com a escola, grau de engenhosidade, auto-estima, senso de responsabilidade, crescimento cívico e social, e outros atributos desejáveis juntamente com o êxito acadêmico. Entretanto, esses indicadores devem ser expandidos para refletir fatores que estruturam as experiências de escolarização dos estudantes:

- Quem ensina o quê e a quem? (Como é a distribuição das especialidades pedagógicas e das oportunidades curriculares?)

- Como o tempo é distribuído em relação às atividades e disciplinas?

- Quais as oportunidades de cada criança obter sucesso e desenvolver seus pontos fortes?

- Quais os tipos de oportunidades extra ou co-curriculares disponíveis? Quantas crianças podem participar?

- Como os professores e estudantes são agrupados para receber informações? Quais são as probabilidades de cada criança ter um adulto que a represente, que a conheça intimamente e que possa ser responsável pelo seu bem-estar?

- Como e com que freqüência os pais são envolvidos nas atividades da escola e nas suas decisões? Quais decisões cabem aos estudantes? E aos professores e demais profissionais da escola? 
- Como é usado o tempo de aula? Quanto tempo é despendido em aulas expositivas, trabalhos em sala de aula, projetos dos alunos, trabalhos de laboratório, produção de textos, solução de problemas? Que tipo de tarefas os estudantes devem desenvolver?

- Que tipo de material didático os estudantes encontram? Eles variam por classe, grupo ou nível?

- O que os estudantes pensam sobre suas experiências escolares? Quais os aspectos de sua experiência acham motivantes? Quais aspectos são desencorajadores?

- O que os pais pensam sobre as experiências escolares dos seus filhos?

- Quais aspectos das experiências pessoais dos estudantes são importantes contribuições para suas experiências escolares e para os esforços da escola em estabelecer ligação com os pais? (Por exemplo, estrutura e circunstâncias familiares, distância entre a casa e a escola, emprego fora da escola, e assim por diante.)

Com questões como essas, conduzindo o desenvolvimento de indicadores, o grupo de professores pode usar seus achados para tomar decisões bem fundamentadas, identificar áreas nas quais pretenda efetuar mudanças e estabelecer quadros de referência a fim de medir seus sucessos.

\section{A Escola e além da Escola como Unidade}

Embora as análises centradas na escola possam fornecer dados preciosos para algumas questões educacionais, a escola é uma unidade de análise muito pequena ou grande demais. Por exemplo, escolas com cursos diferentes ou outras formas de agrupamento educacional oferecem aos estudantes uma variedade muito grande de oportunidades de aprendizagem. Assim, é importante saber não apenas se a escola oferece cálculo, por exemplo, mas quais estudantes podem fazer esse curso - e quais outras disciplinas de matemática existem para aqueles estudantes que não possam se inscrever em cálculo. Da mesma forma, os professores das disciplinas dos cursos gerais são tão bem treinados quanto os das disciplinas dos cursos acadêmicos? Na mesma linha, se uma escola contém equipamentos de informática, os computadores podem estar sendo disponibilizados de forma diferenciada para os estudantes dos cursos gerais e dos acadêmicos? Além disso, as formas como os computadores são 
utilizados - para exercícios, para programação e para a solução de problemas - podem ser diferentes, dependendo do curso freqüentado pelo aluno.

Ao mesmo tempo, para responder questões de eqüidade, como desagregação ou finanças escolares, deve-se ir além do nível escolar dos dados. Por exemplo, há boas evidências de que fórmulas educacionais estatais colocam em desvantagem sistemas urbanos em alguns Estados e distritos rurais pobres em relação a outros. Nos distritos urbanos, a alocação de recursos também tende a discriminar as escolas mais pobres (que normalmente atendem a uma população não branca). Dessa forma, para os pais estarem seguros de que seus filhos estão recebendo recursos equivalentes, os recursos disponíveis nas suas escolas devem ser comparados com os de outras escolas, no distrito e fora dele.

\section{Indicadores como Incentivos}

As pesquisas consistentemente sugerem que as pessoas produzem mais nas áreas em que são avaliadas. Isso explica porque a avaliação é tão poderosa. Os indicadores não apenas medem a realidade, mas também a mudam. Quando os indicadores vêm atrelados a recompensas certificação escolar, incentivos financeiros, aprovação dos estudantes e conclusão de curso, entre outras - é possível prever mudanças no comportamento com grande certeza (Haney, Madaus, 1986). Dependendo das circunstâncias, do tipo de medida, e das recompensas atreladas, os indicadores podem deixar de medir o que originalmente deveriam medir (Darling-Hammond, 1988).

Como se observou, os efeitos de indicadores atrelados a recompensas podem, às vezes, ser contraprodutivos. Por exemplo, quando professores e dirigentes escolares recebem prêmios de acordo com a média dos resultados dos estudantes na própria escola, dois incentivos imediatos são criados: a não aceitação pelas escolas e a exclusão de estudantes com baixos escores; a transferência de professores e administradores capacitados para as escolas que atendem alunos em desvantagem educacional. Obviamente, nenhum desses dois resultados serve aos objetivos da política. O que ocorre é que as escolas se tornam menos responsáveis em vez de mais.

Por outro lado, indicadores bem concebidos e que são usados criteriosamente podem servir como incentivos positivos para a melhoria das escolas. Se os indicadores da aprendizagem estudantil encorajarem os estudantes e professores a focalizar o trabalho em habilidades $\mathrm{e}$ 
capacidades importantes, se ajudarem a identificar necessidades ou problemas de modo que esses possam ser examinados da melhor forma, então servirão de base para uma escolarização comprometida. Do mesmo modo, se os indicadores do contexto escolar ou do desempenho ajudarem os professores e a comunidade escolar a monitorar a qualidade e a igualdade de oportunidades disponível para os alunos, se eles fornecerem informações ricas para a solução de problemas baseadas na própria escola, então servirão de base para processos decisórios responsáveis e, em longo prazo, para uma educação mais responsável.

\section{REFERÊNCIAS BIBLIOGRÁFICAS}

ARCHBALD, D.; NEWMANN, F. M. Beyond standardized resting: assessing authentic academic achievement in the secondary school. Reston, VA: National Association of Secondary School Principals, 1988.

ASCHER, C. Can performance-based assessments improve urban schooling? Digest N 66. New York: ERIC Clearinghouse on Urban Education Teachers College, Columbia University, 1990.

Urban school finance: The quest for equal opportunity. Digest $\mathrm{N}$ 55. New York: ERIC Clearinghouse on Urban Education Teachers College, Columbia University, 1989. (ED 311 147)

BOYER, E. High school. New York: Harper and Row, 1983.

CARNEGIE Council on Adolescent Development. Turning points: preparing youth for the 21st century. New York: Carnegie Corporation of New York, 1989.

COALITION of Essential Schools. Performances and exhibitions: The demonstration of mastery. Horace, v. 6, n.3, March 1990.

DARLING-HAMMOND, L. Accountability for professional practice. Teachers College Record, 1989.

Assessment and incentives: the medium is the message. The AAHE Assessment Forum. Third National Conference on Assessment in Higher Education, Chicago, June 8-11, 1988.

Indicators and policy. Paper prepared for the Organization of Economic Cooperation and Development. Paris: OECD, 1990a. 
DARLING-HAMMOND, L. Teacher professionalism: Why and how? In: LIEBERMAN, A. (ed.) Schools as collaborative cultures: creating the future now. Bristol, PA: Falmer Press, 1990c. p.25-50.

Teacher quality and equality. In: GOODLAD, J.; KEATING, P. (eds.) Access to knowledge: an agenda for our nation's schools. New York: College Entrance Examination Board, 1990b.

DARLING-HAMMOND, L.; WISE, A. E. Beyond standardization: state standards and school improvement. The Elementary School Journal, v.85, n.3, p. 315-336, 1985.

FRACHTER, N. Rethinking school reform. Social Policy, v. 20, n.2, p.16-25, 1989.

GOODLAD, J. A place called school: prospects for the future. New York: McGraw Hill, 1984. (ED 236 137)

HANEY, W.; MADAUS, G. Effects of standardized testing and the future of the national assessment of educational progress. Working paper prepared for the NAEP study group. Chestnut Hill, MA: Center for the Study of Testing Evaluation and Education Policy. 1986.

HOLMES, C. T.; MATTHEWS, K. M. The effects of non promotion on elementary and junior high school pupils: a meta-analysis. Review of Educational Research, n. 54, p. 225-236, 1984.

KORETZ, D. A framework for evaluating and validating indicators of mathematics and science education. Santa Monica, CA: RAND Corporation, 1989.

Arriving in Lake Wobegon: are standardized tests exaggerating achievement and distorting instruction? American Educator, v. 12, n. 2, p. 8$15,46-52,1988$.

LIEBERMAN, A.; MILLER, L. Restructuring schools: What matters and what works. Phi Delta Kappan, v. 71, n.10, p. 759-764, jun. 1990.

MADAUS, G. et al. The sensitivity of measures of schools effectiveness. Harvard Education Review, v. 49, n. 2, p. 207-229, 1979.

MCDONNELL, L. M. Restructuring American Schools: the promise and the pitfalls. New York: Institute on Education and the Economy, Teachers College, Columbia University, 1989. (ED 314 547). 
McDONNELL, L. M.; OAKES, J. Creating responsible and responsive accountability systems. Report of the OERI Study Group on State Accountability Reporting. Santa Monica, C. A: Rand Corporation, 1988.

NATIONAL Assessment of Educational Progress (NAEP). Reading, thinking, and writing: results from the 1979-80. National Assessment of Reading and Literature. Denver: Author, 1981.

OAKES, J. What education indicators? The case for assessing the school context. Education Evaluation and Policy Analysis, v. 11, n. 2, p.181-199, 1989.

Educational indicators: a guide of policymakers. New Brunswick: Rutgers University, Center for Policy Research in Education, October 1986. (ED 315 920)

OAKES, J. et al. Multiples inequalities: the effects of race, social class, and ability grouping on access and mathematics education. Santa Monica, CA: Rand Corporation, 1990.

OERI State Accountability Study Group. Creating responsible and responsive accountability systems. Report of the OERI Study Group. Washington DC: US. Department of Education, Office of Educational Research and Information, 1988. (ED 299 706)

US Department Of Education. White paper on accountability: tying assessment to action. Washington, DC: Author, 1987.

WISE, A. E.; GENDLER, T. Rich schools, poor schools: the persistence of unequal education. The College Board Review, n. 151, p. 12-27, 1989.

Recebido em: janeiro 2006

Aprovado para publicação em: setembro 2006 